\title{
Pemeriksaan Tajam Penglihatan pada Anak dan Refraksi Siklopegik: Apa, Kenapa, Siapa?
}

Julita

\begin{abstract}
Abstrak
Tajam penglihatan merupakan indikator primer kesehatan mata dan sistem visual. Tajam penglihatan didefinisikan sebagai kemampuan seseorang untuk melihat suatu objek. Pemeriksaan tajam penglihatan pada anak-anak memerlukan teknik, metode tertentu, dan tergantung kondisi pasien. Pemeriksaan refraksi yang dilakukan pada anak-anak dengan menggunakan siklopegik. Metode: Studi tinjauan pustaka dari berbagai literatur. Hasil: Pemeriksaan tajam penglihatan anak pada usia preverbal (kurang dari 2,5 tahun) yaitu dapat dilakukan dengan observasi, fiksasi, oftalmoskopi, refleks pupil, optokinetic nystagmus test (OKN), the prefential looking test, dan visual evoked potential (VEP). Sedangkan pemeriksaan tajam penglihatan pada anak usia verbal (lebih dari 2,5 tahun) yaitu dengan menggunakan optotype seperti Allen card, HOTV card, LEA symbol, E chart, dan Snellen chart. Refraksi siklopegik merupakan gold standard pemeriksaan refraksi pada anak karena dapat mencegah akomodasi sehingga dapat menghindari terjadinya kesalahan hasil pemeriksaan refraksi pada anak. Kesimpulan: Pemeriksaan tajam penglihatan pada anak dapat dibedakan berdasarkan usia yaitu preverbal dan verbal. Refraksi siklopegik merupakan gold standard pemeriksaan refraksi pada anak.
\end{abstract}

Kata kunci: Pemeriksaan tajam penglihatan anak, preverbal, verbal, refraksi siklopegik

\begin{abstract}
Visual acuity is the primary indicator of eye health and visual systems. Visual acuity is ability of person to see an object. Visual acuity examination in children requires techniques, methods, and cooperation on patient. Examination of refraction in children is by cyclopegic. Method:Literature review from various literatures. Result: The assesment of visual acuity examination in children divided to preverbal and verbal age. The preverbal age is less than 2.5 years and verbal age is more than 2.5 years. Visual acuity examination in preverbal age are observation, fixation, ophthalmoscopy, pupil reflex, optokinetic nystagmus test (OKN), the prefential looking test, and visual evoked potential (VEP). Visual acuity examination in verbal age are Allen card, HOTV card, LEA symbol, E chart, and Snellen chart. Cyclopegic refraction is the gold standard of refraction examination in children, because can be prevent the accommodation and avoid error results of refraction examination in children.Conclusion:The assesment of visual acuity examination in children can be distinguished by preverbal and verbal age. Cyclopegic refraction is the gold standard of refraction examination in children.
\end{abstract}

Keywords: visual acuity examination in children, preverbal, verbal, cyclopegic refraction

Affiliasi penulis : bagian ilmu kesehatan mata FK. Unand Korespondensi : Julita julita.afdal@yahoo.com Telp: [Company Phone]

\section{PENDAHULUAN}

Tajam penglihatan merupakan indikator primer kesehatan mata dan sistem visual. Tajam penglihatan didefinisikan sebagai kemampuan seseorang untuk melihat suatu objek. .,2,3 $^{1}$

Pemeriksaan tajam penglihatan pada orang dewasa normal biasanya sudah familiar dan nyaman untuk dilakukan, tetapi pemeriksaan tajam penglihatan pada anak-anak memerlukan teknik, metode, dan cara untuk memperoleh kerja sama tergantung pada kondisi pasien..$^{4,5}$

Anak-anak bukanlah orang dewasa kecil dan memiliki banyak permasalahan salah satunya anatomi mata dan tajam penglihatan yang masih berkembang sehingga diperlukan deteksi dini. Setiap tahap perkembangan anak-anak membutuhkan perbedaan pemeriksaan oftalmologi untuk mengetahui perkembangan visual. Persiapan yang tepat dan sikap dokter yang baik dapat menyebabkan pemeriksaan oftalmologi pada anak-anak menjadi nyaman. ${ }^{2,3}$

Pemeriksaan refraksi subjektif pada anakanak tidak efektif dilakukan sehingga pemeriksaan yang dilakukan yaitu pemeriksaan refraksi objektif. Selain itu pemeriksaan refraksi gold standard yang dilakukan pada anak-anak yaitu dengan siklopegik sehingga dapat mencegah akomodasi. ${ }^{4,5}$

Pada tinjauan pustaka ini akan dibahas pemeriksaan tajam penglihatan pada anak dan refraksi siklopegik.

ISI

\section{Definisi Tajam Penglihatan}

Tajam penglihatan adalah pengukuran secara angular yang berkaitan dengan jarak pemeriksaan untuk melihat ukuran obyek minimal pada jarak tertentu. Hal ini merupakan kemampuan untuk membedakan dua stimulus yang terpisah dalam ruang dengan latar belakang kontras yang tinggi. ${ }^{2,3}$ 


\section{Teknik Pemeriksaan Tajam Penglihatan pada Anak}

Pemeriksaan penglihatan pada anak merupakan bagian penting dalam pemeriksaan mata secara komprensif. Pemeriksaan tajam penglihatan pada anak sulit dilakukan, karena mereka sering merasa takut dan sulit untuk berkonsentrasi. Oleh karena itu, dalam melakukan pemeriksaan harus dengan cepat dan akurat dan sangat dibutuhkan kondisi dimana si anak tertarik pada pemeriksaan kita. Kondisi ini harus kita ciptakan dengan berbagai cara, misalnya dengan menyapa dan mengajak salaman, dengan memuji atau memberikan perhatian kepada sesuatu yang dipakainya seperti baju, sepatu dan rambutnya atau memberikan mainan yang berwarna menarik. Pemeriksaan tajam penglihatan harus di sesuaikan dengan umur, kooperatif, kondisi neurologik, dan kemampuan membaca pasien. ${ }^{4,5,6}$

Pemeriksaan tajam penglihatan pada anak dapat dibedakan berdasarkan usia yaitu preverbal dan verbal. Pemeriksaan tajam penglihatan anak pada usia preverbal yaitu usia kurang dari 2,5 tahun dan verbal pada usia lebih dari 2,5 tahun. Pemeriksaan tajam penglihatan anak pada usia preverbal yaitu dapat dilakukan dengan observasi, fiksasi, oftalmoskopi, refleks pupil, optokinetic nystagmus test $(\mathrm{OKN})$, the prefential looking test, dan visual evoked potential (VEP)..$^{4,5}$

\section{Observasi}

Pada metode ini kita dapat mengamati apakah anak tampak melihat atau peduli terhadap lingkungan sekitarnya? Apakah anak respon terhadap lingkungan sosial seperti mengenali wajah pemeriksa atau anggota keluarganya.? Apakah anak melihat jari tangan dan kakinya sendiri? Adanya pengenalan dan perhatian anak menunjukkan tajam penglihatannya baik. Metode ini sulit dinilai pada anak yang keterbelakangan mental, karena mungkin anak tersebut melihat, tetapi tidak respon terhadap sekitar. ${ }^{4,6}$

\section{Fiksasi dan mengikuti benda}

Pada teknik ini kita lihat apakah anak tetap terfiksasi pada objek yang menarik. Apakah anak mengikuti objek yang menarik tersebut. Respon anak mengikuti objek ini biasanya didapatkan pada 1 atau 2 bulan kehidupan dan ini membuktikan bahwa visus anak baik. ${ }^{4}$

Untuk melihat fiksasi pada mata anak juga dapat digunakan metode CSM. Metode ini dapat digunakan pada anak yang belum dapat berbicara.

C : Sentral. Lokasi reflek kornea pada saat pasien berfiksasai dengan cahaya senter dengan 1 mata ditutup (monokuler). Normal reflek kornea ada pada sentral kornea. Jika eksentrik disebut dengan uncentral (UC).

S : Steadines. Artinya tetap. Fiksasi pada senter saat digerakan dan diam (monokuler). Jika tidak tetap disebut unsteady (US).

$\mathrm{M}$ : Maintain Aligment. Kemampuan pasien untuk mempertahankan kelurusan mata dengan cara satu mata ditutup kemudian dibuka. Jika tidak mampu mempertahankan disebut Unmaintain (UM). ${ }^{4,5}$

\section{Oftalmoskopi}

Oftalmoskopi langsung atau pun tidak langsung dipakai untuk mengetahui keadaan media mata dan mempelajari karakteristik fisik dari retina dan nervus optikus. Terdapatnya media yang jernih dan retina yang utuh dengan nervus optikus yang yang normal dapat menunjukan bahwa tajam penglihatan baik. $^{4,5}$

\section{Reflek Pupil}

Adanya reflek langsung dan tidak langsung pupil terhadap cahaya menunjukkan bahwa jalur aferen dan eferen reflek pupil baik. Cara sederhana yang dipakai untuk memeriksa reflek ini dapat digunakan untuk menilai keadaan saraf penglihatan bagian depan. Tapi respon normal dari pemeriksaan ini belum mengindikasikan bahwa pasien dapat melihat, hanya menunjukan penyampaian sinyal ke korteks. Jika cahaya senter pada satu mata menyebabkan konstriksi pada kedua pupil berarti retina, nervus optikus, traktus optikus berfungsi baik. $4,5,7$

\section{Optokinetic Nystagmus Test (OKN)}

Optokinetic Nystagmus Test merupakan sebuah silinder yang dapat berputar pada sumbunya dan pada dindingnya terdapat garis-garis tegak yang mempunyai ketebalan tertentu, Tes ini sangat berguna untuk mengetahui fungsi penglihatan pada anak. Dengan memutar alat ini di depan mata anak akan terlihat nistagmus pada mata anak tersebut yang gerakannya berlawanan dengan arah perputaran slinder. Semakin halus garis yang terdapat pada tabung slinder yang memberikan respon nistagmus maka semakin baik pula visus bayi yang diperiksa (Gambar 1). 4,5

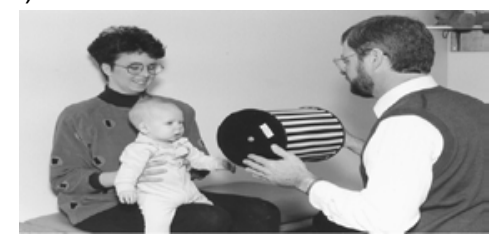

Gambar 1. Optokinetic Nystagmus Test. ${ }^{4}$

\section{Prefential Looking Test}

Preferential looking test menilai ketajaman penglihatan dengan mengamati respon anak terhadap stimulus visual. Pemeriksaan ini cukup detail untuk menilai tajam penglihatan pada bayi dan anak yang belum bisa bicara. Preferential looking test dapat dilakukan dengan menggunakan Teller Acuity Card II dan Cardiff Acuity Test. ${ }^{6,7}$

Teller Acuity Card II merupakan serangkaian kartu persegi panjang yang terdiri dari 17 kartu yang berukuran masing-masing $25,5 \mathrm{~cm} \times 55,5 \mathrm{~cm}$ dan terdapat garis-garis hitam dan putih yang dicetak dengan latar belakang abu-abu. Kartu ini terbagi menjadi dua sisi dengan lubang di bagian tengah yang mempunyai diameter $4 \mathrm{~mm}$ dan garis-garis tersebut hanya terdapat pada satu sisi kartu saja. Gerakan mata ke arah sisi dengan garis menunjukkan bahwa anak mampu melihat garis-garis tersebut. Lebar garis menurun secara berturut-turut. Semakin tipis garis yang bisa terlihat maka semakin baik tajam penglihatan anak. Pemeriksaan ini dilakukan secara monokular dengan menutup salah satu mata dan secara binokular (Gambar 2). 6,7

Pada pemeriksaan visus dengan teller acuity test, jarak pemeriksaan ditentukan berdasarkan usia anak. Pada bayi usia 0-6 bulan pemeriksaan dilakukan pada jarak $38 \mathrm{~cm}$, pada anak usia 7 bulan hingga 3 
tahun pemeriksaan dilakukan pada jarak $55 \mathrm{~cm} .4,6,7$
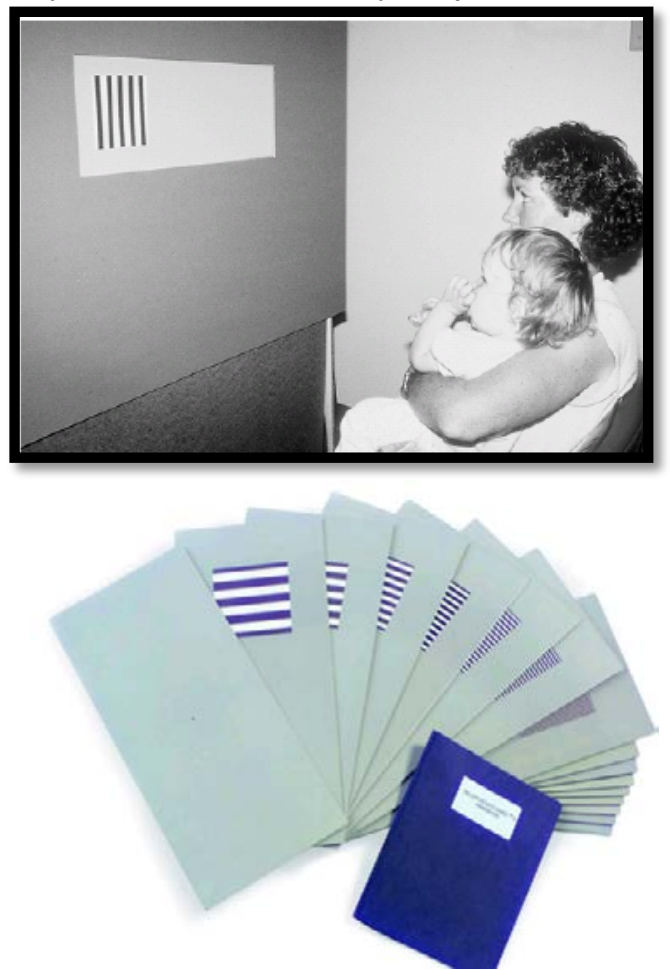

Gambar 2. Prefential looking test. ${ }^{4}$

Pada anak dengan usia lebih dari 3 tahun pemeriksaan pada jarak $84 \mathrm{~cm}$ dan pada anak dengan tajam penglihatan yang lebih buruk pemeriksaan dilakukan pada jarak yang lebih dekat $9.5 \mathrm{~cm}$ dan 19 $\mathrm{cm}$. Sebelum memulai pemeriksaan, pemeriksaan harus memastikan jarak mana yang digunakan dan kemudian tajam penglihatan dinilai dengan menggunakan tabel konversi visus berdasarkan pada level kartu yang bisa dilihat (dalam cy/cm) dengan jarak pemeriksaan (Tabel 1). . $, 7,8^{\circ}$

Tabel 1. Tabel konversi visus dengan Teller Acuity Test. $^{8}$

CONVERSIONS FROM CYCLESICM TO SNELLEN EQUIVALENTS'

\begin{tabular}{|c|c|c|c|c|c|}
\hline \multirow[t]{2}{*}{ CYCLES/CM } & \multicolumn{2}{|c|}{ IEST DISTANCE $^{+}$} & \multicolumn{3}{|c|}{ TEST DISTANCE $^{+}$} \\
\hline & $\underline{9.5 \mathrm{~cm}}$ & $19 \mathrm{~cm}$ & $38 \mathrm{~cm}$ & $55 \mathrm{~cm}$ & $84 \mathrm{~cm}$ \\
\hline 38.0 & $20 / 57$ & $20 / 40$ & $20 / 23$ & $20 / 16$ & 20/11 \\
\hline 26.0 & $20 / 84$ & $20 / 59$ & $20 / 33$ & $20 / 24$ & $20 / 15$ \\
\hline 19.0 & $20 / 110$ & $20 / 81$ & $20 / 45$ & $20 / 32$ & $20 / 21$ \\
\hline 13.0 & $20 / 170$ & $20 / 120$ & $20 / 66$ & $20 / 47$ & $20 / 31$ \\
\hline 9.80 & $20 / 220$ & $20 / 160$ & $20 / 89$ & $20 / 63$ & $20 / 41$ \\
\hline 6.50 & $20 / 340$ & $20 / 240$ & $20 / 130$ & $20 / 94$ & $20 / 63$ \\
\hline 4.80 & $20 / 460$ & $20 / 320$ & $20 / 180$ & $20 / 130$ & $20 / 84$ \\
\hline 3.20 & $20 / 680$ & $20 / 490$ & $20 / 270$ & $20 / 190$ & $20 / 130$ \\
\hline 2.40 & $20 / 910$ & $20 / 650$ & $20 / 360$ & $20 / 260$ & $20 / 170$ \\
\hline 1.60 & $20 / 1400$ & $20 / 970$ & $20 / 540$ & $20 / 380$ & $20 / 250$ \\
\hline 1.30 & $20 / 1700$ & $20 / 1200$ & $20 / 670$ & $20 / 470$ & $20 / 310$ \\
\hline 0.86 & $20 / 2500$ & $20 / 1800$ & $20 / 1000$ & $20 / 710$ & $20 / 470$ \\
\hline 0.64 & $20 / 3300$ & $20 / 2400$ & $20 / 1400$ & $20 / 960$ & $20 / 630$ \\
\hline 0.43 & $20 / 4800$ & $20 / 3500$ & $20 / 2000$ & $20 / 1400$ & $20 / 940$ \\
\hline 0.32 & $20 / 6400$ & $20 / 4700$ & $20 / 2700$ & $20 / 1900$ & $20 / 130$ \\
\hline 0.23 & & & & & \\
\hline
\end{tabular}

\section{Visual Evoked Potential (VEP)}

Tes Visual Evoked Potential (VEP) merupakan pemeriksaan kualitatif dari pemeriksaan tajam penglihatan. Tes ini digunakan untuk melihat ada atau tidaknya kebutaan kortek. Alat ini berupa elektroensefalogram (EEG) yang diambil dari lobus oksipital. Elektroda primer ditempelkan di atas lobus oksipital. VER ditentukan dengan menstimulasi mata dengan cahaya terang, dengan mengunakan suatu alat perekam aktivitas listrik otak lewat stimulasi cahaya pada retina. Pemeriksaan ini lebih bermanfaat pada anak dengan retardasi mental. ${ }^{4,5}$

Sedangkan pemeriksaan tajam penglihatan pada anak usia verbal yaitu dengan menggunakan optotype seperti Allen card, HOTV card, LEA symbol, E chart, dan Snellen chart. ${ }^{4,5,9}$

\section{Allen Card}

Allen Card berupa gambar yang sudah dikenal oleh anak-anak misalnya gambar mobil, pohon natal, boneka beruang, telepon dan kue ulang tahun. Allen card digunakan pada usia anak 2,5 tahun. Pemeriksaan dilakukan dengan jarak 3 meter (Gambar 3). 5,9

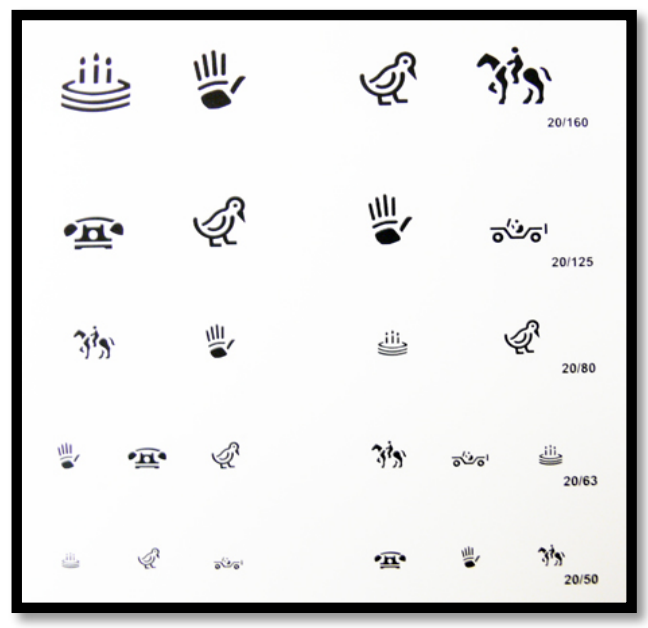

Gambar 3. Allen card.

\section{The Stycard Test (HOTV card)}

Pada pemeriksaan ini digunakan satu set simbol dengan ukuran yang bertingkat, dan satu set simbol yang masing-masing bertuliskan Huruf $\mathrm{H}, \mathrm{O}, \mathrm{T}, \mathrm{V}$ sebagai interpretasi dengan meminta anak menunjukan huruf yang sama dengan yang ditunjuk oleh pemeriksa. HOTV card digunakan pada usia anak 30-54 bulan. Pemeriksaan dilakukan dengan jarak 3 meter (Gambar 4). 4,5,9

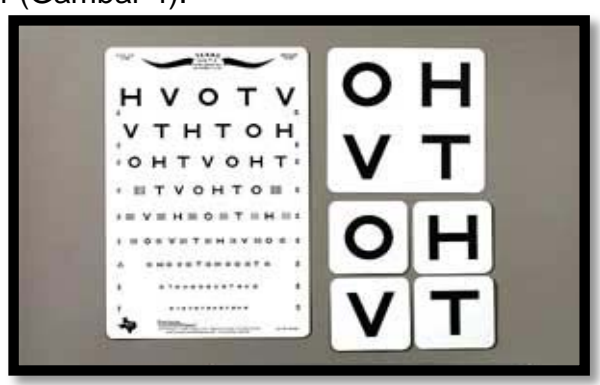

Gambar 4. HOTV card. ${ }^{5}$

\section{LEA symbol}

Lea symbol terdiri atas 4 buah gambar yaitu apel, rumah, lingkaran, dan persegi empat. LEA symbol digunakan pada anak usia 3-3,5 tahun. Anak diminta untuk mengenal masing-masing gambar kemudian anak menunjukkan gambar yang ada. Nilai berapa visus anak sesuai dengan angka yang berada di samping LEA symbol (Gambar 5).4,9,10 


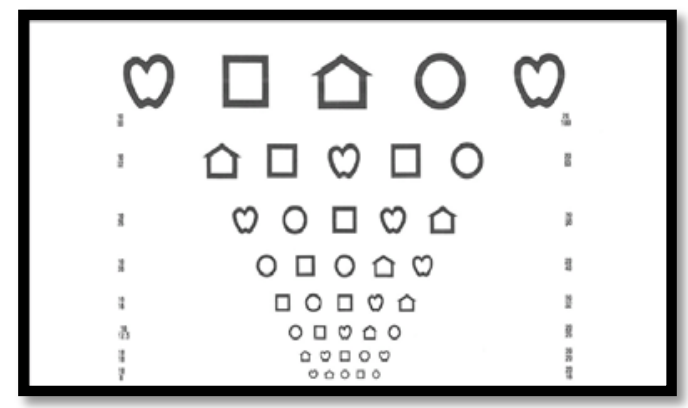

Gambar 5. LEA symbol. ${ }^{4}$

4. E chart

Pemeriksaan dengan metode ini hampir sama dengan pemeriksaan kartu snellen, bedanya pemeriksan ini hanya menggunakan satu huruf " $E$ " dengan berbagai ukuran dan posisi. Tanyakan kepada anak kemana arah dari kaki Huruf ' $E$ ' apakah ke bawah, ke atas, ke kiri atau ke kanan. E chart dapat digunakan pada usia di atas 4 tahun. ${ }^{4,10,11}$

\section{$2.3 \quad$ Refraksi siklopegik}

Refraksi siklopegik merupakan gold standard pemeriksaan refraksi pada anak karena dapat mencegah akomodasi sehingga dapat menghindari terjadinya kesalahan hasil pemeriksaan refraksi pada anak. $^{4,5}$

Terdapat berbagai jenis obat siklopegik yang dapat digunakan pada anak (Tabel 2). ${ }^{4}$

Tabel 2. Jenis obat siklopegik. ${ }^{4}$

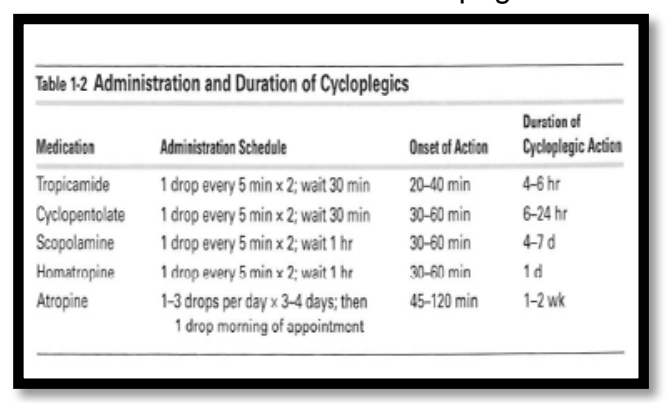

DAFTAR PUSTAKA

1. Skuta GL, Cantor LB, Weiss JS. Decreased Vision in Infants and Children. Pediatric Ophthalmology and Strabismus. USA: American Academy of Ophthalmology. 2015. pp. 189-194.

2. Kniestedt C, Stamper RL. Visual Acuity and Its Measurement.In: Ophthalmology Clinics of North America. USA; Elsevier. 2003. pp 155170

3. Dubois L. Visual Acuity. In Clinical Skills for The Ophthalmic Examination. Ledford KL, Daniels K, Campbell R, ED. Atlanta; Slack Incorporated. 2006. pp.14-20

4. Wright KW, Hengst TC, Spiegel PH. NeuroOphthalmology. Pediatric Ophthalmology and Strabismus: Springer New York; 2013. pp. 865-878.

5. Skuta GL, Cantor LB, Weiss JS. The Pediatric Eye Examination. Pediatric Ophthalmology and Strabismus. USA:American Academy of Ophthalmology; 2015. pp. 5-14.

6. Rovick L. Testing Visual Acuity in Children and Non-Verbal Adults. Association of Technical Personnel in Ophthalmology. 2012. pp 85-92.
7. Wilson ME, Saunders RA, Trivedi RH. The Art and Science of Examining a Child. Pediatric Ophthalmology Current Thought and a Practical Guide. Germany: Springer. 2009. pp 1-6.

8. Sharma P, Bairagi D, Sachdeva MM, Kaur K, Khokhar S, Saxena R. Comparative Evaluation of Teller and Cardiff Acuity Tests in Normals and Unilateral Amblyopes in under Two-Year-Olds. Indian Journal of Ophthalmology. 2003; 51(4). pp 341-345.

9. Nelson LB. Harley's pediatric ophthalmology. 2014

10. Duckman RH. Infant, Toddler, and Children's Visual Acuity Practical Aspects. Visual Development, Diagnosis, and Treatment of the Pediatric Patient: Lippincott Williams \& Wilkins. 2006. pp 190-204.

11. Stout AU. Pediatric Eye Examination. Handbook of Pediatric Strabismus and Amblyopia. Germany: Springer. 2006. pp 123. 